\title{
Personality Traits as Predictors of Self-Regulated Learning and Academic Engagement among College Students in Ghana: A Dimensional Multivariate Approach
}

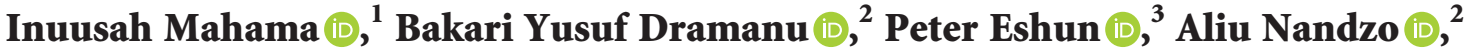 \\ David Baidoo-Anu $\mathbb{1}^{4},{ }^{4}$ and Mavis Ansu Amponsah $\mathbb{1}^{5}$ \\ ${ }^{1}$ Department of Counselling Psychology, University of Education, Winneba, Ghana \\ ${ }^{2}$ Department of Education and Psychology, University of Cape Coast, Cape Coast, Ghana \\ ${ }^{3}$ Department of Educational Foundations, University of Education, Ghana \\ ${ }^{4}$ Queen's University, Faculty of Education, Duncan McArthur Hall 511 Union Street, Kingston, Ontario K7M 5R7, Canada \\ ${ }^{5}$ Department of Education, Berekum College of Education, Berekum, Ghana
}

Correspondence should be addressed to Inuusah Mahama; imahama@uew.edu.gh

Received 11 November 2021; Accepted 7 February 2022; Published 7 March 2022

Academic Editor: Ayoub Bahnasse

Copyright (c) 2022 Inuusah Mahama et al. This is an open access article distributed under the Creative Commons Attribution License, which permits unrestricted use, distribution, and reproduction in any medium, provided the original work is properly cited.

\begin{abstract}
The study explored personality traits as they predicted self-regulated learning and academic engagement among college students in Ghana. A sample of 652 (return rate was 87.0\%) was drawn from an accessible population of 17,396. Adapted versions of Taiwanese Short Self-Regulation Questionnaire (22 items; $\alpha=0.84$ ), University Student Engagement Inventory (15 items; $\alpha=0.81$ ), and Big-Five Personality Inventory (30 items; $\alpha=0.70$ ) were used for the data collection. The data collected were analysed using multivariate multiple regression. The study revealed that student-teachers exhibited lower levels of self-regulated learning and academic engagement. Again, openness, conscientiousness, extraversion, and agreeableness aspects of the personality traits predicted self-regulated learning and academic engagements of students. Findings from this study serve as a beacon for teacher education programs in Ghana to scale up their efforts in ensuring that preservice teachers are able to self-regulate their learning. As preservice teachers who will soon be practicing, they cannot help their students self-regulate their learning if they themselves have low levels of self-regulation and engagement. Students' success can only be realized when learners are able to manage their own learning and engage in academic activities.
\end{abstract}

\section{Introduction}

There appears to be an increasing concern about students' engagement globally. Extant literature shows the significant role self-regulated learning and student engagement play in supporting students' academic success [1-5]. In lieu of this, educators globally have been called to enact policies that leverage self-regulated learning and students' engagement. Self-regulation, according to Zimmerman [5], is the degree to which learners are motivated, exhibit metacognition, and behaviourally involved in their learning process for goal attainment. This means that self-regulation espouses the cognitive, metacognitive, behavioural, motivational, and emotional/affective aspects of learners. As a result, selfregulation serves as a unique umbrella in which a wide range of learning-related variables (e.g., self-efficacy, volition, and cognitive strategies) are studied in a systematic and holistic manner [3].

In view of Hoyle [6], people who are able to self-regulate themselves effectively could manage their perceptions about their social surroundings, demonstrate consistent positive behaviours, and succeed in goals they set for themselves. Weimer [7] alleged that self-regulation is universal for every learner and does not mean that it is a trait that may exist in 
some students and not in others. Rather, it entails the selection of and utilisation of specific processes (goal setting, monitoring progress, efficient use of time, and self-evaluation of selected methods) that must be individually adapted to various learning tasks. Mirhashemi and Goodarzi [2] equally indicated that learners' ability to monitor their motivation and emotions is important for their learning.

On the other hand, students' engagement pertains to students' active participation in activities: studying, skill acquisition, search for knowledge, and research in the learning environment [8]. Students' engagement has an influence on students' academic performance, especially on students' grade point average (GPA) [9]. Carini et al. [9] intimated that academic engagement is an important driver of both the academic success of students and the overall positive study experiences of students. An understanding of the learning behaviours of students in educational institutions enables stakeholders in the educational process the opportunity to gauge how the instructional processes are carried out [10]. Students' engagement is used as a channel to improve low levels of academic achievement, reduce students' boredom, and disaffection [11]. Students' engagement is perceived as a strong indicator of optimal studying experience and a pillar to students' success [4]. In a similar study, Fredricks et al. [1] viewed students' engagement as a multifaceted concept that encompasses three dimensions: behavioural (involvement in academic and social or extracurricular activities), cognitive (incorporating thoughtfulness and willingness to exert the effort necessary to comprehend complex ideas and master difficult skills), and emotional (positive and negative reactions to teachers, classmates, academics, and school). He argued that knowing the extent of students' engagement academically gives teachers and other school authorities the impetus to plan effective teaching methods that will make the most use of the learning behaviours of students.

Over the last decade, self-regulated learning and students' engagement have been explored in tandem with students' personality traits [12-14], Ozan, Gundogdu, Bay, and Celkan $[15,16]$. It has been observed that students differ significantly and have distinct behavioural patterns that help to explain their individual identity. In lieu of this, there has been a surge of interest in personality traits (particularly the five-factor model) in relation to education and learning [17]. Personality is a distinct and relatively permanent way of thinking, feeling, and acting that defines a person's reaction to a situation [18]. For instance, it has been observed that personality type influenced the various learning strategies that students adopted [14]. The five-factor model, which is the most common and empirically sound model of personality research, focuses on five categories or dimensions (i.e., personality traits) such as openness to experience (o), extraversion, conscientiousness, agreeableness, and neuroticism (Big-5) [17].

The next section of the study discusses the literature review, theoretical models, Ghanaian context, methods and results, discussion, conclusions, implication for policy, and practice limitations and suggestions for future studies.

\section{Literature Review}

2.1. Personality Traits and Students' Self-Regulated Learning (SRL). In Turkey, 310 randomly sampled university students were examined in terms of their level of self-regulated learning by Ozan et al. [15]. These researchers found that students' perception on their metacognitive self-regulation was moderate. In a similar study, Dörrenbächer and Perels [19] investigated personality traits and SRL strategies using a survey sample of 337 undergraduate students with different specializations such as preservice teaching, psychology, language and cultural studies, economics, law, and natural sciences. The study revealed that low levels of neuroticism moderately and highly predicted self-regulated learning components identified in students. Furthermore, the study revealed that higher levels of extraversion, conscientiousness, agreeableness, and openness in students predicted a moderate to high SRL strategies used by students. These studies provide evidence that reflect how personality traits significantly shapes student self-regulated learning strategies.

Moreover, Bruso [13] found that students with extraversion, conscientiousness, agreeableness, and openness, but not neuroticism, predicted more frequent use of SRL strategies. Bruso's findings support the work of Ghyasi et al. [14] who explored the relationship between personality types and self-regulated learning strategies of language students in Iran. Using a sample of 231 undergraduate students, the study revealed that personality traits influenced the various learning strategies that students adopted. Particularly, the findings also showed that students who reported high on conscientiousness, in most cases, could use all strategies, especially when it came to managing time and study environment, and those who scored high on extraversion were more likely to use peer learning and other help-seeking strategies. Majority of researchers who investigated the relationship between students' personality traits and selfregulated learning found that students with high levels of openness, conscientiousness, extraversion, and agreeableness exhibited behaviours of goal attainment, mindfulness, adjustment, proactiveness, and goal setting in their learning $[2,12,14,20,21]$. It is conspicuous that these behavioural exhibitions (i.e,, goal attainment, mindfulness, adjustment, proactiveness, and goal setting in their learning) are an effective recipe for effective self-regulated learning $[12,21]$.

\subsection{Personality Traits and Students' Academic Engagement.} Many empirical works have focused on the relationship between personality traits and student engagement in different contexts with varied findings $[22,23]$. Additionally, Qureshi et al. [16] explored whether personality can moderate students' engagement and their attitude towards employability in Edge Hill University, Ormskirk, the United Kingdom. The results showed that different patterns of traits were associated with student engagement. Also, Chapa [24] investigated the influence of personality traits on students' engagement and academic success. The study found that personality traits mediated students' engagement and their 
academic success. In a similar vein, Sangeetha et al. [23] conducted a study among college students and found that the personality characteristics of students contributed significantly to students' learning engagement. That is to say, the personality traits of students had a positive relationship with the extent to which students engaged academically.

Researchers such as Engels et al. [25], Greene and Oswald [26], Montenegro [22], and Ulmannen, Soini, Pietarinen, and Pyhalto (2016) explored students' engagement extensively and found an extra component as agentic engagement. This component is branded as student input to the flow of instruction that they receive in the learning environment. According to Montenegro, students are able to discover ways of enhancing and personalizing their education by providing teachers with opportunities to determine how autonomy-supportive their instruction may be through agentic engagement. Montenegro claimed that this type of engagement is the process of regulating practical behaviours that may change the flow of teaching in the learning environment. In a study among 900,000 students, Gallup (2016) found them to be showing low levels of engagement with $32 \%$, which was contrary to $75 \%$ high levels of engagement they exhibited in their earlier stages of education. This presupposes that as students' progress to college after high school, their engagement reduces. Similarly, Cornell et al. [27] measured student engagement among 87,391 students. The study revealed that the majority of the students possessed high levels of engagement and educational aspirations.

In a study, Komarraju and Karau (2005) found that extraverted and openness personality traits positively related and predicted students' academic engagement. In a study conducted among students, Qureshi et al. [16] found that personality traits produced a significant model that accounted for a reasonable degree of variance in students' general engagement. Specifically, extraversion, agreeableness, and conscientiousness were positive predictors of students' general engagement. However, emotional stability and openness never predicted students' general engagement. Again, the study found that personality traits produced a significant model that accounted for a judicious degree of variance in cognitive engagement, as agreeableness and conscientiousness positively predicted students' cognitive engagement. In contrast, extraversion, emotional stability, and openness did not predict students' cognitive engagement. Personality traits produced a significant model that accounted for a reasonable degree of variance in behavioural engagement, where extraversion, agreeableness, conscientiousness, and openness positively predicted students' behavioural engagement, but emotional stability did not predict students' behavioural engagement. In this study, behavioural engagement was adequately explained by personality, with $30 \%$ variance. Likewise, personality traits produced a significant model that accounted for a reasonable degree of variance in students' emotional engagement. However, neither extraversion, agreeableness, conscientiousness, emotional stability, nor openness predicted students' emotional engagement.
In another study, Ongore [28] suggested that the BigFive personality model is a valuable means for establishing the innate potentiality of students' engagement. Using bivariate analysis, the study revealed that all components of the personality traits were supported with significant predictions. With this engagement, dimensions such as emotional, behavioural, and cognitive correlated high with the personality model $(p<0.01)$. In that regard, extraversion $(r=0.24, p<0.01)$, conscientiousness $(r=0.31, p<0.01)$, and openness to experience $(r=0.40, p<.01)$ positively and significantly predicted students' engagement with high coefficient values, while agreeableness and neuroticism predicted students' engagement with low coefficients $(r=0.23$, $p<0.05$ ). A study conducted among Iranian college students revealed that personality traits predict the dimensions of students' academic engagement. For example, the openness personality trait was found to predict emotional engagement in boys than girls, while openness was found to predict cognitive engagement in girls than boys. Again, conscientiousness and cognitive engagement were positively related, where the conscientiousness personality trait was found to predict cognitive engagement in girls and boys. Furthermore, neuroticism personality trait and cognitive engagement correlated negatively. This presupposes that neurotic personality among the students may exhibit anxiety, fears, doubts, and other problems that could affect their academic and nonacademic performance (Rashedi and Abolmaali, 2014).

\section{Theoretical Models}

3.1. Pintrich Model Self-Regulated Learning. While several SRL frameworks indicate several different structures and processes involved in the process of learning $[5,29,30]$, the paradigm of Pintrich [31] was chosen as a structure because it focuses on specific dimensions of student learning. Pintrich' [31] SRL model spelt out a system that explains students' learning in four perspectives: (a) cognition, (b) motivation and affect, (c) behaviour, and (d) context. Each of the four perspectives of SRL is discussed, where teachers could use techniques to encourage SRL of students for their instruction.

The first field of learning that students are entitled to regulate is techniques for information or learning, such as metacognitive strategies [31]. There are several different cognitive techniques where students are taught using different methods, including rehearsal, learning, and organization (Hofer et al. as cited in [32]). Detailed understanding of learning material has evolved due to comprehensive and systematic approaches. Cognitive management is wellestablished to be central to deep and substantive learning among students (Winne and Hadwin as cited in [32]). Teachers can facilitate the emotional control of students in many respects. Teachers, for example, may encourage students to use specific strategies for studying or doing a job, encouraging students to track their comprehension, measuring their understanding, or training students to learn new information [32]. 
Motivation and affective components are also central components of SRL [31, 33]. Students should control motivation and influence it just as their intellect can be controlled and tracked $[31,34]$. In comparison, interventions to encourage success have improved academic performance over and above certain facets of student SRL and level of skill [35]. The students will not use self-regulation techniques if unmotivated [5]. Students' desires, goals, and beliefs [36] are critical components of their drive for success [37]. Teachers should demonstrate the value of learning assignments to promote student engagement and encourage students to participate in the course material. Students interested in their teachers prefer to enter the classroom [38] to reinforce the social desires of their peers by using humour.

The behavioural dimension of SRL reflects learners' activities, including the quest for support and time management [31]. Students must engage in activities purposefully to enable, facilitate, and support the learning process. Academic support can help enhance the learning and success of students [31]. The use of different learning opportunities and on-campus facilities, such as schools and workshops, contribute to the search behaviours of students. Time management activity, like the development of study schedules, helps guide the learning process and is usually illustrated in SRL [31]. Active self-regulated teachers regularly engage in activities such as counselling and time management to help students meet their academic goals. Teachers may allow students to participate in such activities outside the classroom or encourage positive behavioural control during the regular education era. A teacher may, for example, recommend students visit the campus resource centre to receive assistance with challenging tasks or use it for in-class learning assignments.

SRL environment involves specific factors relevant to teaching assignments, such as environments in the classroom or assignment guidelines [29, 31, 39]. Therefore, the student must use specific strategies to track, adjust, and regulate their learning environment. While students cannot monitor teachers' teaching styles or the quality of their assignments, their classroom environment can be controlled in some ways [31]. The context area or field is not entirely “self-regulated." After all, many students' learning activities and experiences are external and beyond their reach because students control their way of learning. Academic resources such as reviews from professors or assessment work often act as an entity in the SRL phase of learning [40, 41]. Training assignments can help students control awareness, motivation, and impact on behaviour.

\subsection{Engagement Theory by Kearsley and Schneiderman [42].} The purpose behind the engagement philosophy is to create an effective joint team working on ambitious projects that interest individuals outside the classroom. Students must be actively involved in learning experiences through contact with others. The basic idea behind engagement philosophy is that students must be actively involved in the learning process through engaging with others and functioning worthwhile [42]. Although this kind of engagement can exist in theory without using technology, technology may promote engagement in ways that are not otherwise feasible. According to the theory, any project is always designed around the three key components of engagement theory: relate, create, and donate. These three ingredients of engagement theory imply the learning activities are given as project-based learning (relate), problem-solving learning (create), and authentic learning (donate) (an outside focus). Such three approaches result in imagination, meaning, and quality of learning among students [42].

The first component of the engagement theory is projectoriented, collaborative research that involves teamwork, planning, management, and social skills. Students of various backgrounds form their project group and are supervised by the project coordinator or supervisor. Upon preparation, students will have the chance to work successfully on their projects. Students gain experience in all facets of projectbased learning and improve their interpersonal and working relationships. The concept has proved to be a productive tool in the transition from abstract or limited classroom awareness to the broader workforce [43].

Create is the second element of engagement theory, focusing on carving a niche in an unclear learning situation. The question of development is the settlement of learning tasks. In this, students must examine the problem, develop a system, and include it in the real world in the creative process. In reality, learning is innovative and directed at the core element of engagement theory. The students usually have no sense of control over their learning from traditional classroom schooling, but they control complex school tasks. The students then focus on the issue and complete the work with a high standard. The project's focus is the nature of problem-based learning methods (PBLs) [44].

Donate is the third element of the engagement theory. It emphasizes the importance of the learning experience, which is essential and valuable. Students must face real world issues and address significant problems in the real world when working on this initiative. Getting a projectbased group job, they connect with group members, and they eventually get the sense of satisfaction and trust in their skills, which offers us some advantages. The proper learning background of the study, on the other hand, increases enthusiasm for the students. This concept is consistent with the emphasis on school-to-work schemes and the business theory of current company training programs in many school systems and colleges [43]. In applying this philosophy in school, a successful collaborative team is found, where all students partake and contribute in their work [42].

\section{Ghanaian Context}

Analysing how students handle and facilitate their own learning has been a recurring issue in educational research [45]. Scholars have opined that students' characteristics such as their personality type influenced their academic success, particularly when it concerned their self-regulation and academic engagement [14, 23, 24], Ghyasi, Yazdani and Kirabira, 2019; [23]. These studies, therefore, suggest that in seeking to understand and handle the issue of students' 
learning, there is a need to study the relationship between students' personality traits and the way they self-regulate themselves and engage in academic tasks. Empirically, in Ghana, numerous studies have been done, particularly on the relationship between personality traits and students' related characteristics, at different levels of learning across the educational ladder. Most of the previous studies focused on personality traits and students' motivation and academic achievement [46], students' academic engagement and academic performance [47], personality types and academic procrastination [48], personality traits and academic performance [49], and personality traits and students' career preferences [50]. The foregoing studies suggest that students' academic performance is influenced by their personality traits and students' academic engagement. However, within the Ghanaian context, no study has explored the influence of personality traits on students' self-regulation and engagement in the pursuit of their academic courses or programmes. To provide empirical data that will contribute to policy and fill the gap in literature, the study seeks to explore whether personality traits predict self-regulated learning and academic engagement of colleges of education students in Ghana. Based on the purpose of the study, the following research questions were formulated to guide the study:

(1) What is the level of self-regulated learning among students?

(2) What is the level of academic engagement among students?

(3) What is the relationship between students' personality traits and students' self-regulated learning?

(4) What is the relationship between students' personality traits and students' academic engagement?

\section{Methods}

5.1. Research Design. The study employed a quantitative approach to data collection via a questionnaire. Data analysis were done using descriptive and inferential statistics. The study adopted the analytical cross-sectional design because data were collected at one point in time from various categories (zones) of colleges of education in Ghana. Using this design, the researchers were able to establish relationships and predictions among the variables under investigation. According to Kesmodel [51], analytical cross-sectional studies aim to assess associations between different constructs such as attitudes and opinions of people concerning a situation or phenomenon. Wang and Cheng [52] also indicated that this design is used to describe features of a particular population. Advantageously, analytical crosssectional research may be conducted without the need for follow-up, making them easier to perform [53]. According to Wang and Cheng [52], the analytical cross-sectional design gives preliminary evidence in planning a future study in the area. However, the key drawback of analytical cross-sectional studies is that the sequential relation among variables cannot be determined since all are studied at the same time [53].
5.2. Participants. The population for the study was 46,825 students in all 46 colleges of education in Ghana. The accessible population was all level 200 or second-year students in the 46 colleges of education with a population of 17,396 .

5.3. Instruments. The instruments used for data collection were Taiwanese Short Self-Regulation Questionnaire (22 items TSSRQ; $\alpha=0.84$ ) validated by Chen and Lin [54]. The scale had five (5) dimensions; goal attainment (7 items, $\alpha=0.88$ ), mindfulness ( 7 items, $\alpha=0.86$ ), adjustment (3 items, $\alpha=0.84$ ), proactiveness ( 3 items, $\alpha=.80$ ), and goal setting ( 2 items, $\alpha=0.82$ ). The scale was scored based on agreement and disagreement, where strongly disagreed $(\mathrm{SD})=1$, disagreed $(\mathrm{A})=2$, undecided $(\mathrm{U})=3$, agreed $(\mathrm{A})=$ 4 , and strongly agreed $(\mathrm{SA})=5$. The scale had ten negative statements, which were reverse-scored. The University Student Engagement Inventory (15 items USEI, $\alpha=0.81$ ) developed by Marco et al. [55] was also used. The scale had three (3) dimensions such as emotional engagement (5 items, $\alpha=0.88$ ), cognitive engagement (5 items, $\alpha=0.82$ ), and behavioural engagement ( 5 items, $\alpha=0.74$ ). The scale was scored based on agreement and disagreement, where strongly disagreed $(\mathrm{SD})=1$, disagreed $(\mathrm{A})=2$, not sure $(\mathrm{U})=3$, agreed $(\mathrm{A})=4$, and strongly agreed $(\mathrm{SA})=5$. The Big-Five Personality Inventory (30 items; Big-Five, $\alpha=0.70$ ) developed by Soto and John [56] was used. The scale had five (5) dimensions such as openness (6 items, $\alpha=0.65$ ), conscientiousness ( 6 items, $\alpha=0.69$ ), extraversion ( 6 items, $\alpha=0.77$ ), agreeableness ( 6 items, $\alpha=0.70$ ), and neuroticism (6 items, $\alpha=0.68$ ). The scale was scored based on agreement and disagreement, where strongly disagreed $(\mathrm{SD})=1$, disagreed $(\mathrm{A})=2$, neutral $(\mathrm{N})=3$, agreed $(\mathrm{A})=4$, and strongly agreed $(\mathrm{SA})=5$. With the adoption, the researchers reduced the scales to four-point Likert-type scale, making the scoring denote strongly disagreed $(\mathrm{SD})=1$, disagreed $(\mathrm{A})=2$, agreed $(\mathrm{A})=3$, and strongly agreed $(\mathrm{SA})=4$. This scale also had thirteen negative statements, which were reverse-scored. After the adaptation, pilot testing was done among randomly sampled college students whose colleges were not captured in the process of sampling. This process allowed for the establishment of the internal consistencies as indicated by the three scales used. The final data were collected by the researchers from the sampled colleges.

5.4. Procedure. Using a sample of 652 from 26 colleges of education (Gay et al., 2012; Nwana, 1992), proportionatestratified, simple random (lottery method with replacement), and systematic sampling techniques were used to select the respondents. The proportionate-stratified was used because colleges were in their natural strata according to national groupings: central/western (7 colleges), eastern/ greater (9 colleges), Ashanti-Brong-Ahafo (11 colleges), northern (11 colleges), and Volta (8 colleges). Thus, a fair representation of colleges in each stratum was needful. Again, the simple random sampling technique was used to select a varied number of colleges such as central/western (4 colleges sampled), eastern/greater (5 colleges sampled), Ashanti-Brong-Ahafo (6 colleges sampled), northern (6 
TABLE 1: Levels of self-regulated learning.

\begin{tabular}{lccc}
\hline Level & Score range & Frequency & Percentage \\
\hline Low & $22-44$ & 324 & 57.0 \\
Moderate & $45-66$ & 61 & 10.7 \\
High & $67-88$ & 183 & 30.3 \\
Total & 3 & 568 & 100.0 \\
\hline
\end{tabular}

Source: field survey.

colleges sampled), and Volta (5 colleges sampled). The systematic sampling procedure, using $3(46,825 / 17,396)$ as the $K^{\text {th }}$ term, was used to select individual respondents in the sampled colleges.

5.5. Data Analysis. The data collected were analysed quantitatively with multivariate multiple regression because the predictor and criterion variables were measured on multiple levels.

\section{Results}

6.1. What Is the Level of Self-Regulated Learning among Students? The question sought to establish levels of selfregulated learning among students. Providing an answer to the question, 22 items of self-regulated learning questionnaire were used. The questionnaire was 4-point; thus, strongly disagree $=1$, disagree $=2$, agree $=3$, and strongly agree $=4$. In the same questionnaire, some items were reverse-scored (strongly disagree $=4$, disagree $=3$, agree $=2$, and strongly agree $=1$ ) because they are negative statements. The items were transformed, where low, moderate, and high levels were computed using frequencies and percentages against score ranges of 22-44, 45-66, and 67-88. Table 1 provides the results.

Table 1 provides the results on the levels of self-regulated learning among students. It was found that the majority of the students possessed low levels of self-regulated learning abilities $(n=324,57.0 \%$; range $=22-44)$, while some possessed high levels of regulated learning abilities $(n=183$, $30.3 \%$; range $=67-88$ ) and few possessed moderate levels of self-regulated learning abilities $(n=61, \quad 10.7 \%$; range $=45-66$ ). These findings contrast the findings of Ozan et al. [15] and Dörrenbächer and Perels [19] who found moderate and high levels of self-regulated learning among practicing teachers and preservice teachers.

6.2. What Is the Level of Academic Engagement among Students? The question sought to establish levels of academic engagement among students. Providing an answer to the question, 15 items of academic engagement questionnaires were used. The questionnaire was 4-point; thus, strongly disagree $=1$, disagree $=2$, agree $=3$, and strongly agree $=4$. The items were transformed, where low, moderate, and high levels were computed using frequencies and percentages against score ranges of 15-30, 31-45, and 46-60. Table 2 provides the results.

Table 2 provides results on the level of academic engagement among students. The study found that the majority
TABLE 2: Levels of academic engagement.

\begin{tabular}{lccc}
\hline Level & Score range & Frequency & Percentage \\
\hline Low & $15-30$ & 210 & 37.0 \\
Moderate & $31-45$ & 169 & 29.8 \\
High & $46-60$ & 189 & 30.4 \\
Total & 3 & 568 & 100.0 \\
\hline
\end{tabular}

Source: field survey.

of the students possessed a low level of academic engagement $(n=210,37.0 \%$; range $=15-30)$, while some possessed a high level of academic engagement $(n=189,30.4 \%$; range $=46-60)$ and a few possessed a moderate level of academic engagement $(n=169,29.8 \%$; range $=31-45)$. The findings support the work of Gallup (2016) who found that college students have low levels of engagement in classrooms.

6.3. Personality Traits Will Predict Students' Self-Regulated Learning. The focus of this hypothesis was to test whether or not the dimensions of the personality traits could predict self-regulated learning abilities of students. In multivariate multiple regression (MMR), personality trait as the predictor was multidimensional (openness, conscientiousness, extraversion, agreeableness, and neuroticism) and self-regulated learning as the criterion was also multidimensional (goal attainment, mindfulness, adjustment, proactiveness, and goal setting). After satisfying assumptions such as normality, linearity, homoscedasticity, and multicollinearity, a stringent alpha level was set to avoid type I error (rejecting the null hypothesis when indeed, there are no significant results) because the criterion variable had multiple dimensions. In doing this, the Bonferroni adjustment suggested by Tabachnik and Fidel [57] was used, where the researchers divided the original alpha by the number of dimensions of the criterion variable. Thus, $0.05 / 5=0.010$, as 0.010 served as the new alpha level. Table 3 provides the results.

Table 3 provides results of the test of multivariate multiple regression (MMR), where openness, conscientiousness, extraversion, agreeableness, and neuroticism played the roles of predictors to the criteria goal attainment, mindfulness, adjustment, proactiveness, and goal setting. Using Wilk's lambda to test for the omnibus hypothesis that all beta values across the dependent variables equalled to zero was statistically significant. Thus, $F(5,558)=5.05$, Wilk's lambda $=0.957$, and $p \leq .010$, with self-regulated goal attainment as the criterion, $R^{2}=0.147, p \leq 0.010$. This shows that $14.7 \%$ of the variance in self-regulated goal attainment was explained by personality traits such as openness, conscientiousness, extraversion, agreeableness, and neuroticism. With self-regulated mindfulness as the criterion, $R^{2}=0.176, p \leq 0.010$. This shows that $17.6 \%$ of the variance in self-regulated mindfulness is explained by personality traits such as openness, conscientiousness, extraversion, agreeableness, and neuroticism. With self-regulated adjustment as the criterion, $R^{2}=0.197, p \leq 0.010$. This shows that $19.7 \%$ of personality traits such as openness, conscientiousness, extraversion, agreeableness, and neuroticism explained its variance. With self-regulated proactiveness as 
TABLE 3: Dimensional multivariate multiple regression (MMR) results for personality trait (PT) and self-regulated learning (SRL).

\begin{tabular}{|c|c|c|c|c|c|c|}
\hline Effect & Value & $F$ & Hypothesis df & Error df & Sig. & Partial eta squared \\
\hline Wilks' lambda & 0.957 & 5.05 & 5.000 & 558.00 & 0.000 & 0.043 \\
\hline Self-regulated learning (SRL) & Parameter & B & Std. Error & $\mathrm{t}$ & Sig. & Partial eta squared \\
\hline \multirow{6}{*}{ Goal attainment } & Intercept & 13.634 & 1.379 & 9.886 & 0.000 & 0.148 \\
\hline & Openness & 0.164 & 0.055 & 2.995 & 0.003 & 0.016 \\
\hline & Conscientiousness & 0.262 & 0.048 & 5.479 & 0.000 & 0.051 \\
\hline & Extraversion & 0.145 & 0.050 & 2.883 & 0.004 & 0.015 \\
\hline & Agreeableness & 0.018 & 0.045 & 0.398 & 0.691 & 0.000 \\
\hline & Neuroticism & -0.077 & 0.042 & -1.807 & 0.071 & 0.006 \\
\hline \multirow{6}{*}{ Mindfulness } & Intercept & 5.882 & 1.989 & 2.957 & 0.003 & 0.015 \\
\hline & Openness & 0.032 & 0.079 & 0.402 & 0.688 & 0.000 \\
\hline & Conscientiousness & 0.300 & 0.069 & 4.346 & 0.000 & 0.033 \\
\hline & Extraversion & 0.291 & 0.072 & 4.021 & 0.000 & 0.028 \\
\hline & Agreeableness & 0.226 & 0.064 & 3.517 & 0.000 & 0.022 \\
\hline & Neuroticism & -0.103 & 0.061 & -1.677 & 0.094 & 0.005 \\
\hline \multirow{6}{*}{ Adjustment } & Intercept & 3.104 & .796 & 3.899 & 0.000 & 0.026 \\
\hline & Openness & 0.095 & 0.032 & 3.021 & 0.003 & 0.016 \\
\hline & Conscientiousness & 0.117 & 0.028 & 4.252 & 0.000 & 0.031 \\
\hline & Extraversion & 0.089 & 0.029 & 3.060 & 0.002 & 0.016 \\
\hline & Agreeableness & 0.104 & 0.026 & 4.039 & 0.000 & 0.028 \\
\hline & Neuroticism & -0.038 & 0.024 & -1.571 & 0.117 & 0.004 \\
\hline \multirow{6}{*}{ Proactiveness } & Intercept & 6.752 & 0.946 & 7.133 & 0.000 & 0.083 \\
\hline & Openness & 0.136 & 0.037 & 3.634 & 0.000 & 0.023 \\
\hline & Conscientiousness & 0.062 & 0.033 & 1.883 & 0.060 & 0.006 \\
\hline & Extraversion & 0.031 & 0.034 & 0.910 & 0.363 & 0.001 \\
\hline & Agreeableness & -0.039 & 0.031 & -1.281 & 0.201 & 0.003 \\
\hline & Neuroticism & -0.098 & 0.029 & -3.379 & 0.001 & 0.020 \\
\hline \multirow{6}{*}{ Goal setting } & Intercept & 0.807 & 0.772 & 1.044 & 0.297 & 0.002 \\
\hline & Openness & -0.049 & 0.031 & -1.594 & 0.112 & 0.004 \\
\hline & Conscientiousness & 0.051 & 0.027 & 1.893 & 0.059 & 0.006 \\
\hline & Extraversion & 0.135 & 0.028 & 4.800 & 0.000 & 0.039 \\
\hline & Agreeableness & 0.072 & 0.025 & 2.892 & 0.004 & 0.015 \\
\hline & Neuroticism & 0.049 & 0.024 & 2.050 & 0.041 & 0.007 \\
\hline
\end{tabular}

${ }^{\mathrm{a}} R$-squared $=0.147$ (adjusted $R$-squared $\left.=0.139\right)$. ${ }^{\mathrm{b}} R$-squared $=0.176$ (adjusted $R$-squared $=0.169$ ). ${ }^{\mathrm{c}} R$-squared $=0.197$ (adjusted $R$-squared $\left.=0.190\right)$. ${ }^{\mathrm{d}} R$ squared $=0.052$ (adjusted $R$-squared $=0.044)$. ${ }^{\mathrm{e}} R$-squared $=0.098$ (adjusted $R$-squared $=0.090$ ). Source: field survey.

the criterion, $R^{2}=0.052, p \leq 0.010$. This shows that $5.2 \%$ of personality traits such as openness, conscientiousness, extraversion, agreeableness, and neuroticism explained its variance. With self-regulated goal setting as the criterion, $R^{2}=0.098, p \leq 0.010$. This shows that personality traits such as openness, conscientiousness, extraversion, agreeableness, and neuroticism explained $9.8 \%$ of its variance. For dimensional predictions, it was individually based. Using selfregulated goal attainment as a criterion, only agreeableness (beta $=0.018 ; t=0.398 ; p \geq 0.691$; partial eta square $=0.000$ ) and neuroticism (beta $=-0.077 ; t=-1.807 ; p \geq 0.071$; partial eta square $=0.006)$ personality traits did not predict, but openness (beta $=0.164 ; t=2.995 ; p \leq 0.003$; partial eta square $=0.016$ ), conscientiousness (beta $=0.262 ; t=5.479$; $p \leq 0.000$; partial eta square $=0.051$ ), and extraversion (beta $=0.145 ; t=2.883 ; p \leq 0.004$; partial eta square $=0.015$ ) personality traits positively predicted with small effect sizes. The results imply that students with personality types such as openness, extraversion, and conscientiousness are likely to regulate their learning towards goal attainment, but this will be higher in conscientious students than extraverted and open students. The revelation supports that of Bidjerano and
Dai [12] who found conscientiousness and openness to be related to self-regulated learning components of students. Again, using self-regulated mindfulness as a criterion, only openness (beta $=0.032 ; t=0.402 ; p \geq 0.688 ;$ partial eta square $=0.000)$ and neuroticism (beta $=-0.103 ; t=-1.677$; $p \geq 0.094$; partial eta square $=0.005$ ) personality traits did not predict, but conscientiousness (beta $=0.300 ; t=4.346$; $p \leq 0.000$; partial eta square $=0.033$ ), extraversion (beta $=0.291 ; t=4.021 ; p \leq 0.001$; partial eta square $=0.028$ ), and agreeableness (beta $=0.226 ; t=3.517 ; p \leq 0.001$; partial eta square $=0.022$ ) personality traits positively predicted with small effect sizes. The results imply that students with personality types such as conscientiousness, extraversion, and agreeableness are likely to regulate their learning by being mindful of the learning task, situation, and process, but this will be prominent in students with conscientious personality types than extraverted and agreeable personality types. The current study findings are in line with Bruso [13] study revelation, which showed that students with extraversion, conscientiousness, agreeableness, and openness but not neuroticism predicted more frequent use of SRL strategies by students. 
Furthermore, using self-regulated adjustment as a criterion, only neuroticism (beta $=-0.038 ; t=-1.571 ; p \geq 0.117$; partial eta square $=0.004)$ personality trait did not predict, but openness (beta $=0.095 ; t=3.021 ; p \leq 0.001$; partial eta square $=0.016$ ), conscientiousness (beta $=0.117$; $t=4.252$; $p \leq 0.001$; partial eta square $=0.031$ ), extraversion (beta $=0.089 ; t=3.060 ; p \leq 0.001$; partial eta square $=0.016$ ), and agreeableness (beta $=0.104 ; t=4.039 ; p \leq 0.001$; partial eta square $=0.028$ ) personality traits positively predicted with small effect sizes. These results imply that students with personality types such as openness, conscientiousness, extraversion, and agreeableness are likely to regulate their learning by adjusting to diverse unpredictable situations during the learning expedition, but this will be higher in students with conscientiousness personality type than those with agreeableness, extraversion, and openness types of personality. The current study findings support Ghyasi et al.' [14] study revelation, which showed that personality traits influenced the various learning strategies that students adopted.

More so, using self-regulated proactiveness as a criterion, conscientiousness (beta $=0.062 ; t=1.883 ; p \geq 0.060$; partial eta square $=0.006$ ), agreeableness (beta $=-0.039$; $t=-1.281 ; p \geq 0.201$; partial eta square $=0.003)$, and extraversion (beta $=0.031 ; t=0.910 ; \quad p \geq 0.363$; partial eta square $=0.001)$ personality traits did not predict, but openness (beta $\left.=0.136 ; t=3.634 ; p \geq 0.001 ; \eta^{2} \mathrm{p}=0.023\right)$ and neuroticism (beta $=-0.098 ; t=-3.379 ; p \leq 0.001$; partial eta square $=0.020$ ) personality traits positively and negatively predicted with small effect sizes. The results imply that students with openness personality type are likely to regulate their learning in a proactive manner as they could be active and involved in the process, while students with neuroticism personality type are likely not to regulate their learning in a proactive manner as they could be anxious, irritable, selfdoubt, sad, and above all exhibit poor emotions. The current study findings corroborate with Bidjerano and Dai [12] and Ghyasi et al. [14] study findings, where high levels of openness, conscientiousness, extraversion, and agreeableness exhibited by students could lead them to goal attainment, mindfulness, adjustment, proactiveness, and goal setting behaviours.

Last, using self-regulated goal setting as a criterion, only openness (beta $=-0.049 ; t=-1.594 ; p \geq 0.112$; partial eta square $=0.004)$ and conscientiousness (Beta $=0.051$; $t=1.893 ; p \geq 0.059$; partial eta square $=0.006$ ) personality traits did not predict, but extraversion (beta $=0.135$; $t=4.800 ; p \leq 0.001$; partial eta square $=0.039$ ), agreeableness (beta $=0.072 ; t=2.892 ; p \leq 0.004$; partial eta square $=0.015$ ), and neuroticism (beta $=0.049 ; t=2.050 p \leq 0.041$; partial eta square $=0.007$ ) personality traits positively predicted with small effect sizes. The results imply that students with personality types such as extraversion, agreeableness, and neuroticism are likely to regulate their learning towards a goal setting, but this will be higher in students with extraversion type of personality than those with agreeableness and neuroticism types of personality. In part, the current study findings support Eilam et al. [21] and Mirhashemi and Goodarzi [2] studies' outcomes such as personality traits of conscientiousness, openness, and agreeableness significantly influenced students' self-regulated learning and their academic achievement.

6.4. Personality Traits Will Predict Students' Academic Engagement. The focus of this hypothesis was to test whether or not the dimensions of the personality traits could predict academic engagement of students. In multivariate multiple regression (MMR), personality trait as the predictor was multidimensional (openness, conscientiousness, extraversion, agreeableness, and neuroticism) and academic engagement as the criterion was also multidimensional (behavioural engagement, emotional engagement, and cognitive engagement). After satisfying assumptions such as normality, linearity, homoscedasticity, and multicollinearity, a stringent alpha level was set to avoid type I error (rejecting the null hypothesis, where indeed, there are no significant results) because the criterion variable had multiple dimensions. In doing this, the Bonferroni adjustment suggested by Tabachnik and Fidel [57] was used, where the researchers divided the number of dimensions with the original alpha level; thus, $0.05 / 5=0.017$, as 0.017 served as the new alpha level. Table 4 provides the results.

Table 4 provides results on the test of multivariate multiple regression (MMR), such as openness, conscientiousness, extraversion, agreeableness, and neuroticism that played the roles of predictors to criteria such as behavioural engagement, emotional engagement, and cognitive engagement. Using Wilk's lambda to test for the omnibus hypothesis, all beta values across the dependent variables that equalled to zero were statistically significant; thus, $F$ (3, $560)=16.03$, Wilk's lambda $=0.983$, and $p \leq 0.017$. With academic behavioural engagement as the criterion, $R^{2}=0.191, p \leq 0.017$. This shows that $19.1 \%$ of personality traits such as openness, conscientiousness, extraversion, agreeableness, and neuroticism explained its variance. With academic emotional engagement as the criterion, $R^{2}=0.092$, $p \leq .017$. This shows that $9.2 \%$ of personality traits such as openness, conscientiousness, extraversion, agreeableness, and neuroticism explained its variance. With academic cognitive engagement as the criterion, $R^{2}=0.093, p \leq 0.017$. This shows that $9.3 \%$ of personality traits such as openness, conscientiousness, extraversion, agreeableness, and neuroticism explained its variance.

For dimensional predictions, it was individually based. Using academic behavioural engagement as a criterion, only neuroticism (beta $=-0.036 ; t=-0.934 ; p \geq 0.351$; partial eta square $=0.002)$ personality trait did not predict, but openness (beta $=0.120 ; \quad t=2.387 ; \quad p \leq 0.017$; partial eta square $=0.010$ ), conscientiousness (beta $=0.283 ; t=6.419$; $p \leq 0.000$; partial eta square $=0.068$ ), extraversion (beta $=0.114 ; t=2.466 ; p \leq 0.014$; partial eta square $=0.011$ ), and agreeableness (beta $=0.083 ; t=2.021 ; p \leq 0.044$; partial eta square $=0.007$ ) personality traits positively predicted with small effect sizes. The results imply that students with personality types such as openness, conscientiousness, extraversion, and agreeableness are likely to exhibit academic behavioural engagement, but this will be higher in 
TABLE 4: Dimensional multivariate multiple regression (MMR) results for personality trait (PT) and academic engagement (AE).

\begin{tabular}{|c|c|c|c|c|c|c|}
\hline Effect & Value & $F$ & Hypothesis df & Error $\mathrm{df}$ & Sig. & Partial eta squared \\
\hline Wilks' lambda & 0.983 & 3.23 & 3.00 & 560.00 & 0.022 & 0.017 \\
\hline Academic engagement (AE) & Parameter & B & Std. error & $t$ & Sig. & Partial eta squared \\
\hline \multirow{6}{*}{ Behavioural } & Intercept & 6.641 & 1.270 & 5.229 & 0.000 & 0.046 \\
\hline & Openness & 0.120 & 0.050 & 2.387 & 0.017 & 0.010 \\
\hline & Conscientiousness & 0.283 & 0.044 & 6.419 & 0.000 & 0.068 \\
\hline & Extraversion & 0.114 & 0.046 & 2.466 & 0.014 & 0.011 \\
\hline & Agreeableness & 0.083 & 0.041 & 2.021 & 0.044 & 0.007 \\
\hline & Neuroticism & -0.036 & 0.039 & -0.934 & 0.351 & 0.002 \\
\hline \multirow{6}{*}{ Emotional } & Intercept & 7.635 & 1.405 & 5.435 & 0.000 & 0.050 \\
\hline & Openness & -0.001 & 0.056 & -0.021 & 0.984 & 0.000 \\
\hline & Conscientiousness & 0.142 & 0.049 & 2.915 & 0.004 & 0.015 \\
\hline & Extraversion & 0.150 & 0.051 & 2.942 & 0.003 & 0.015 \\
\hline & Agreeableness & 0.125 & 0.045 & 2.750 & 0.006 & 0.013 \\
\hline & Neuroticism & 0.016 & 0.043 & 0.370 & 0.711 & 0.000 \\
\hline \multirow{6}{*}{ Cognitive } & Intercept & 7.541 & 1.334 & 5.655 & 0.000 & 0.054 \\
\hline & Openness & 0.134 & 0.053 & 2.533 & 0.012 & 0.011 \\
\hline & Conscientiousness & 0.129 & 0.046 & 2.777 & 0.006 & 0.014 \\
\hline & Extraversion & 0.059 & 0.049 & 1.212 & 0.226 & 0.003 \\
\hline & Agreeableness & 0.123 & 0.043 & 2.843 & 0.005 & 0.014 \\
\hline & Neuroticism & 0.022 & 0.041 & 0.529 & 0.597 & 0.000 \\
\hline
\end{tabular}

${ }^{\mathrm{a}} R$-squared $=0.191$ (adjusted $R$-squared $=0.184$ ), significant, 0.017. ${ }^{\mathrm{b}} R$-squared $=0.092$ (adjusted $R$-squared $=0.083$ ). ${ }^{\mathrm{c}} R$-squared $=0.093$ (adjusted $R$ squared $=0.085$ ). Source: field survey.

conscientious students than extraverted, open, and agreeable students. The findings of this study support a study revelation of Qureshi et al. [16] who found different patterns of personality traits associated and predicting with students' academic engagement. Again, using academic emotional engagement as a criterion, openness (beta $=-0.001$; $t=-0.021 ; p \geq 0.984$; partial eta square $=0.000)$ and neuroticism (beta $=-0.016 ; t=0.370 ; p \geq 0.711$; partial eta square $=0.000)$ personality traits did not predict, but conscientiousness (beta $=0.142 ; t=2.915 ; p \leq 0.004$; partial eta square $=0.015), \quad$ extraversion $\quad($ beta $=0.150 ; \quad t=2.942$; $p \leq 0.003$; partial eta square $=0.015$ ), and agreeableness (beta $=0.125 ; t=2.750 ; p \leq 0.006$; partial eta square $=0.013$ ) personality traits positively predicted with small effect sizes. The results imply that students with personality types such as conscientiousness, extraversion, and agreeableness are likely to show academic emotional engagement, but this will be prominent in students with extraverted personality types than those with conscientious and agreeable personality types. The findings of this study support that of Sangeetha et al. [23] who found that personality characteristics of students contributed significantly to students' learning engagement. Last, using academic cognitive engagement as a criterion, extraversion (beta $=-0.059 ; t=-1.212 ; p \geq 0.226$; partial eta square $=0.003$ ), and neuroticism (beta $=0.022$; $t=0.529 ; p \geq 0.597$; partial eta square $=0.000$ ) personality traits did not predict, but openness (beta $=0.134 ; t=2.533$; $p \leq 0.012$; partial eta square $=0.011$ ), conscientiousness (beta $=0.129 ; t=2.777 ; p \leq 0.006$; partial eta square $=0.014$ ), and agreeableness (beta $=0.123 ; t=2.843 p \leq 0.005$; partial eta square $=0.014$ ) personality traits positively predicted with small effect sizes. The results imply that students with personality types such as openness, conscientiousness, and agreeableness are likely to show academic cognitive engagement, but this will be higher in students with agreeable type of personality than those with conscientiousness and openness types of personality. This current study findings support Ongore [28] study findings. Ongore found that all components of the personality traits predicted emotional, behavioural, and cognitive engagement of students.

\section{Discussion}

Gleaning from the results, it is conspicuous that students in various colleges in Ghana have low levels of self-regulated learning and student's engagement. However, considering the significant role self-regulated learning and student engagement play in supporting students' academic success [1-5], the majority of the students may not be able to succeed academically. Because these students are likely not to be mindful of their learning situations, they may find it difficult to adjust to tough academic situations [5]. They may also lack proactiveness and the ability to set realistic goals for themselves $[12,14,20,21]$. Similarly, because most students in our study have low levels of academic engagement, they are likely to be less engaged in the classroom, as the quest for academic involvement may seem to be diminished. This may pose a challenge to students in terms of progressing academically, experiencing less academic satisfaction, exhibition of academic avoidant behaviours, and experiencing academic emotional problems $[2,9,10,14]$.

Again, the findings from this study anchored the significant role personality traits play in self-regulation and academic engagement. For example, it is evident from the findings that students with extraversion, agreeableness, and neuroticism personalities are likely to regulate their learning to improve their achievement. According to Eilam et al. [21] 
and Mirhashemi and Goodarzi [2], the personality traits of students are vital avenues to help students take ownership of their own learning. Having knowledge of students' personality traits is a preliminary and important step to identify the kind of self-regulated learning strategy that will be appropriate for students. Similarly, the study reveals that students with personality types such as conscientiousness, extraversion, and agreeableness are likely to exhibit academic emotional engagement. These students with personality types such as conscientiousness, extraversion, and agreeableness are likely to be actively engaged in the classroom, which is an important element for students' success $[23,28]$.

\section{Conclusions}

Understanding who you are, personalizing your learning, and making efforts to be engaged academically are important ingredients for the educational success of tertiary students. With the call for independent student thinkers in most tertiary educational institutions, it is evident that such qualities can be nurtured in students through self-regulated learning and academic engagement based on their personality types. As found in the current study, most of the students possessed low levels of self-regulated learning and academic engagement. This calls for concern as personalizing and owing their studies might be a challenge for the students. Personality traits such as openness, extraversion, conscientiousness, and agreeableness mostly predict aspects of self-regulated learning and academic engagement of students. The findings of the study further accentuate the significant role that personality trait plays in students' engagement in the classroom, self-regulated learning. In as much as providing teaching and learning resources and educational infrastructure as a great way to augment students' engagement and achievement (Adane, 2013; [58, 59]), helping students to take ownership of their own learning is a vital step to support teaching and learning and improve students' academic gains [12, 20, 47]. Therefore, future efforts to promote self-regulated learning and academic engagement abilities in students must take into consideration the individual personality traits, so that the right or best technique could be employed.

\section{Implication for Policy and Practice}

The findings from this study serve as a beacon for teacher education programs in Ghana to scale up their efforts in ensuring that preservice teachers have the capability to selfregulate their learning. As preservice teachers who will soon translate to in-service or practicing teachers, they cannot effectively help their students self-regulate and become active in class if they themselves have low levels of selfregulation and classroom engagement. Students' success can only be realized when learners have a greater motivation to manage their own learning and engage in academic activities. Given that personality traits play a significant role in students' self-regulation, learning, and engagement, such traits that positively predict self-regulated learning should be encouraged and promoted in various colleges.

Again, it is recommended that colleges of education in Ghana should shift from traditional classroom-based teaching to practical-based teaching where students will be offered opportunities (creating learning links and practicing reflective thinking) to own their learning and become engaged in such learning activities. One other factor that has been cited to improve students' self-regulation, learning, and active engagement is self-assessment [60-62]. When students are encouraged to self-assess, they can identify areas they need improvement, which consequently help them to take ownership of their own learning [60-62], consequently improving students' academic gains [20].

\section{Limitations and Suggestions for Future Studies}

This study primarily focused on personality traits as they predicted self-regulated learning and academic engagement of preservice teachers in colleges of education in Ghana. This limits the generalization of this study to preservice teachers in Ghana. Given the importance of this study, we suggest that further studies can be conducted to expound the scope to include students at the basic and second cycle institutions in Ghana. This will help ascertain the levels of self-regulated learning and engagement among the basic and second cycle institutions in the country.

\section{Data Availability}

The data used to support the findings of this study are available from the corresponding author upon request.

\section{Conflicts of Interest}

The authors declare that they have no conflicts of interest.

\section{Authors' Contributions}

All authors contributed equally to this study.

\section{References}

[1] J. A. Fredricks, P. C. Blumenfeld, and A. H. Paris, "School engagement: potential of the concept, state of the evidence," Review of Educational Research, vol. 74, no. 1, pp. 59-109, 2004.

[2] M. Mirhashemi and H. Goodarzi, "Self-regulated learning strategies: the role of personal factors (motivational beliefs and Personality)," Journal of Educational and Management Studies, vol. 4, no. 1, pp. 152-161, 2014.

[3] E. Panadero, "A review of self-regulated learning: six models and four directions for research," Frontiers in Psychology, vol. 8, p. 422, 2017.

[4] Y. Sakurai and K. Pyhältö, "Understanding students' academic engagement in learning amid globalising universities," Annual Review of Comparative and International Education, vol. 34, pp. 31-38, 2018. 
[5] B. J. Zimmerman, "Self-efficacy: an essential motive to learn," Contemporary Educational Psychology, vol. 25, pp. 82-91, 2000.

[6] R. H. Hoyle, "Personality and self-regulation: trait and information processing perspectives," Journal of Personality, vol. 74, no. 6, pp. 1507-1525, 2006.

[7] M. Weimer, "What it means to be a self-regulated learner," Practice, vol. 41, no. 2, pp. 64-70, 2016.

[8] T. Harrison, "Conceptualising student engagement: a cocreation perspective," Working Together to Take Quality Forward, vol. 51, 2013.

[9] R. M. Carini, G. D. Kuh, and S. P. Klein, "Student engagement and student learning: testing the linkages $*$," Research in Higher Education, vol. 47, no. 1, pp. 1-32, 2006.

[10] A. P. Delfino, "Student engagement and academic performance of students of Partido State University," Asian Journal of University Education, vol. 15, no. 1, pp. 1-15, 2019.

[11] National Research Council \& Institute of Medicine, Engaging Schools: Fostering High School Students' Motivation to Learn, National Academy Press, Washington, NJ, USA, 2004.

[12] T. Bidjerano and D. Y. Dai, "The relationship between the bigfive model of personality and self-regulated learning strategies," Learning and Individual Differences, vol. 17, no. 1, pp. 69-81, 2007.

[13] J. L. Bruso, An Examination of Personality Traits as a Predictor of the Use of Self-Regulated Learning Strategies [Unpublished PhD Dissertation in STEM and Professional Studies, Old Dominion University, Norfolk, VA, USA, 2019.

[14] M. Ghyasi, M. Yazdani, and M. A. Farsani, "The relationship between personality types and self-regulated learning strategies of language learners," International Journal of Applied Linguistics \& English Literature, vol. 2, no. 4, pp. 74-82, 2013.

[15] C. Ozan, K. Gundogdu, E. Bay, and H. Y. Celkan, "A study on the university students' self-regulated learning strategies skills and self-efficacy perceptions in terms of different variables," Procedia-Social and Behavioural Sciences, vol. 46, pp. 18061811, 2012.

[16] A. Qureshi, H. Wall, J. Humphries, and A. B. Bahrami-Balani, "Can personality traits modulate student engagement with learning and their attitude to employability?" Learning and Individual Differences, vol. 51, pp. 349-358, 2016.

[17] M. Jensen, "Personality traits, learning and academic achievements," Journal of Education and Learning, vol. 4, no. 4, pp. 91-118, 2015.

[18] M. W. Passer and R. E. Smith, Psychology - the Science of Mind and Behavior, McGraw-Hill, Boston, MA, USA, 2004.

[19] L. Dörrenbächer and F. Perels, "Self-regulated learning profiles in college students: their relationship to achievement, personality, and the effectiveness of an intervention to foster self-regulated learning," Learning and Individual Differences, vol. 51, pp. 229-241, 2016.

[20] N. Babakhani, "The relationship between the big-five model of personality, self- regulated learning strategies and academic performance of islamic azad university students," Procedia Social and Behavioral Sciences, vol. 116, pp. 3542-3547, 2014.

[21] B. Eilam, M. Zeidner, and I. Aharon, "Student conscientiousness, self-regulated learning, and science achievement: an explorative field study," Psychology in the Schools, vol. 46, no. 5, pp. 420-432, 2009.

[22] A. Montenegro, "Understanding the concept of student agentic engagement for learning," Colombian Applied Linguistics Journal, vol. 19, no. 1, pp. 117-128, 2017.
[23] N. Sangeetha, V. Kannan, and A. Savarimuthu, "Personality as a predictor for student engagement," Journal of Advanced Science and Technology, vol. 29, no. 6, pp. 3412-3420, 2020.

[24] F. Chapa, Examination of the Mediating Role of Student Engagement on the Relationship between Personality and Academic Success for Hispanic College Students, Walden University, Minneapolis, Min, USA, 2016.

[25] M. C. Engels, H. Colpin, K. Van Leeuwen et al., "Behavioral engagement, peer status, and teacher-student relationships in adolescence: a longitudinal study on reciprocal influences," Journal of Youth and Adolescence, vol. 45, no. 6, pp. 11921207, 2016.

[26] J. A. Greene, C. A. Oswald, and J. Pomerantz, "Predictors of retention and achievement in a massive open online course," American Educational Research Journal, vol. 52, no. 5, pp. 925-955, 2015.

[27] D. Cornell, K. Shukla, and T. R. Konold, “Authoritative school climate and student academic engagement, grades, and aspirations in middle and high schools," AERA Open, vol. 2, no. 2, pp. 23-32, 2016.

[28] O. Ongore, "A study of relationship between personality traits and job engagement," Procedia-Social and Behavioural Sciences, vol. 141, pp. 1315-1319, 2014.

[29] J. A. Greene and R. Azevedo, "A theoretical review of Winne and Hadwin's model of self-regulated learning: new perspectives and directions," Review of Educational Research, vol. 77, no. 3, pp. 334-372, 2007.

[30] P. H. Winne and A. F. Hadwin, "The weave of motivation and self-regulated learning," Motivation and Self-Regulated Learning: Theory, Research, and Applications, vol. 2, pp. 297-314, 2008.

[31] P. R. Pintrich, "A conceptual framework for assessing motivation and self-regulated learning in college students," Educational Psychology Review, vol. 16, no. 4, pp. 385-407, 2004.

[32] L. D. Hoops, S. L. Yu, Q. Wang, and V. L. Hollyer, "Investigating post-secondary self-regulated learning instructional practices: the development of the self-regulated learning observation protocol," International Journal of Teaching and Learning in Higher Education, vol. 28, no. 1, pp. 75-93, 2016.

[33] D. H. Schunk and B. J. Zimmerman, "Influencing children's self-efficacy and self-regulation of reading and writing through modeling," Reading \& Writing Quarterly, vol. 23, no. 1, pp. 7-25, 2007.

[34] C. A. Wolters, "Understanding procrastination from a selfregulated learning perspective," Journal of Educational Psychology, vol. 95, no. 1, pp. 179-190, 2003.

[35] S. B. Robbins, K. Lauver, H. Le, D. Davis, R. Langley, and A. Carlstrom, "Do psychosocial and study skill factors predict college outcomes? A meta-analysis," Psychological Bulletin, vol. 130, no. 2, pp. 261-273, 2004.

[36] J. Eccles, "Who am I and what am I going to do with my life? Personal and collective identities as motivators of action," Educational Psychologist, vol. 44, no. 2, pp. 78-89, 2009.

[37] S. Hidi and K. A. Renninger, "The four-phase model of interest development," Educational Psychologist, vol. 41, no. 2, pp. 111-127, 2006.

[38] S. E. Gump, "Keep students coming by keeping them interested: motivators for class attendance," College Student Journal, vol. 38, no. 1, pp. 157-161, 2004.

[39] K. R. Lodewyk, P. H. Winne, and D. L. Jamieson-Noel, "Implications of task structure on self-regulated learning and achievement," Educational Psychology, vol. 29, no. 1, pp. 1-25, 2009. 
[40] D. J. Nicol and D. Macfarlane-Dick, "Formative assessment and self-regulated learning: a model and seven principles of good feedback practice," Studies in Higher Education, vol. 31, no. 2, pp. 199-218, 2006.

[41] N. E. Perry and A. Rahim, "Studying self-regulated learning in classrooms: university of British columbia, vancouver, Canada," in Handbook of Self-Regulation of Learning and Performance, pp. 136-150, Routledge, England, UK, 2011.

[42] G. Kearsley and B. Shneiderman, Engagement Theory: A Framework for Technology-Based Teaching and Learning, 1999.

[43] I. Miliszewska and J. Horwood, "Engagement theory: a framework for supporting cultural differences in transnational education," Higher Education Research Society of Australasia, vol. 3, pp. 1-7, 2004.

[44] H. S. Barrows and R. M. Tamblyn, Problem-Based Learning: An Approach to Medical Education, Springer Publishing Company, Berlin, Germany, 1980.

[45] C. Yot-Domínguez and C. Marcelo, "University students' selfregulated learning using digital technologies," International Journal of Educational Technology in Higher Education, vol. 14, no. 1, pp. 1-18, 2017.

[46] K. Nyarko, N. Kugbey, C. M. Amissah, M. Ansah-Nyarko, and B. Q. Dedzo, "The influence of the big five personality and motivation on academic achievement among university students in Ghana," Journal of Education, Society and Behavioural Science, vol. 13, no. 2, pp. 1-7, 2016.

[47] J. O. Essiam, Influence of Student Engagement on Academic Performance in Higher Education in Ghana, Accra, Ghana, 2019.

[48] G. Ocansey, C. Addo, H. K. Onyeaka, J. Andoh-Arthur, and K. Oppong Asante, "The influence of personality types on academic procrastination among undergraduate students," International Journal of School \& Educational Psychology, pp. 1-8, 2020.

[49] E. M. Martey and K. Aborakwa-Larbi, "Assessing the impact of personality traits on academic performance: evidence from tertiary students in Ghana," International Journal of Research Engineering, IT \& Social Science, vol. 6, no. 3, pp. 1-17, 2016.

[50] D. K. Semordzi, S. Odame-Mensah, N. K. Hammond, and I. Amoako, "Moderating role of gender in the relationship between personality trait and career choice among university students," American Journal of Humanities and Social Sciences Research (AJHSSR), vol. 3, no. 6, pp. 198-202, 2019.

[51] U. S. Kesmodel, "Cross-sectional studies-what are they good for?” Acta Obstetricia et Gynecologica Scandinavica, vol. 97, no. 4, pp. 388-393, 2018.

[52] X. Wang and Z. Cheng, "Cross-sectional studies: strengths, weaknesses, and recommendations," Chest, vol. 158, no. 1, pp. 65-71, 2020.

[53] N. Di Girolamo and C. Mans, Research Study Design, WB Saunders, Philadelphia, PA, USA, 2019.

[54] Y. H. Chen and Y. J. Lin, "Validation of the short self-regulation questionnaire for Taiwanese college students (TSSRQ)," Frontiers in Psychology, vol. 9, pp. 259-310, 2018.

[55] J. Maroco, A. L. Maroco, J. A. D. B. Campos, and J. A. Fredricks, "University student's engagement: development of the university student engagement inventory (USEI)," Psicologia: Reflexão e Crítica, vol. 29, no. 21, pp. 1-12, 2016.

[56] C. J. Soto and O. P. John, "Short and extra-short forms of the big five inventory-2: the BFI-2-S and BFI-2-XS," Journal of Research in Personality, vol. 68, pp. 69-81, 2017.

[57] B. Tabachnik and L. Fidel, Using Multivariate Statistics, Allyn \& Bacon, Needham Heights, MA, USA, 2011.
[58] D. Baidoo-Anu, "Perceived school environmental, home conditions and academic performance of junior high school students in asikuma-odoben-brakwa district, Ghana," Journal of Education, Society and Behavioural Science, vol. 24, no. 2, pp. 1-7, 2018.

[59] D. Baidoo-Anu and G. E. Mensah, "The perceptions of junior high school students and teachers towards teaching and learning of integrated science at komenda-edina-eguafoabrim district," Asian Journal of Education and Social Studies, vol. 2, no. 2, pp. 1-8, 2018.

[60] G. T. Brown and L. R. Harris, Student Self-Assessment, Sage, Los Angeles, CA, USA, 2013.

[61] G. Brown and L. Harris, "The future of self-assessment in classroom practice: reframing self- assessment as a core competency," Frontline Learning Research, vol. 3, pp. 22-30, 2014.

[62] E. Panadero, A. Jonsson, and J. Botella, "Effects of self-assessment on self-regulated learning and self-efficacy: four meta-analyses," Educational Research Review, vol. 22, pp. 74-98, 2017. 